\title{
Smooth Sliding Mode Control and Its Application in Ship Boiler Drum Water Level
}

\author{
Sheng Liu, Shiquan Zhao, and Yuchao Wang \\ College of Automation, Harbin Engineering University, Harbin, China \\ Correspondence should be addressed to Yuchao Wang; wangyuchao@hrbeu.edu.cn
}

Received 3 July 2016; Revised 12 October 2016; Accepted 23 October 2016

Academic Editor: R. Aguilar-López

Copyright (C) 2016 Sheng Liu et al. This is an open access article distributed under the Creative Commons Attribution License, which permits unrestricted use, distribution, and reproduction in any medium, provided the original work is properly cited.

In process control, most of the control variables are position quantity which needs to be smooth, such as the opening of valve. In order to get smooth control, a smooth full-order sliding mode controller is proposed. Since the switching term in the proposed method is put into the second derivative of $\operatorname{control} u$, the control $u$ is smooth and its derivative is continuous. The proposed method is tested in drum water level control of the ship boiler, and the results show the effectiveness of the proposed method.

\section{Introduction}

Sliding mode control (SMC) is an effective control method to deal with the plants model uncertainty, load disturbance, and parameters mismatch. And it has been widely studied in the research community. It has been applied in some industrial processes successfully, such as electrical, mechanical, chemical, and aerospace engineering [1]. In SMC, a switching term is adopted, which can cause high frequency oscillations in the system inputs. Due to the chattering phenomenon, its application in practical systems is greatly limited. So elimination of chattering has been one of the main motivations for SMC algorithm, and a number of methods for chattering elimination have been studied [2].

The boundary layer method was proposed [3]. A saturation function is adopted to the SMC strategy, which will increase the steady tracking errors. The high-order sliding modes approach is to hide the discontinuity in its higher derivatives [4-8]. The disturbance estimation method can also be used to attenuate the chattering [9]. The idea of this method is to use the disturbance estimation based on higherorder sliding mode techniques to design a continuous sliding mode control that features second-order nonlinear dynamics in the boundary layer. Chattering-free sliding mode control was proposed for discrete-time system [10]. To avoid the chattering phenomenon, a nonsmooth term (continuous function) was employed instead of the switching term and a reach process is added. Chattering-free terminal sliding mode control was proposed [11]. The singularity problem in terminal sliding mode control system and the chattering problem in both conventional linear sliding mode control and the terminal sliding mode control had been all solved, but this control strategy only gets a continuous control input not a smooth one which is needed in most of process control.

Due to the strong load disturbance, model uncertainties, and parameters mismatch, it is usually difficult to control drum water level of the boiler. And a number of methods have been developed. An adaptive Grey predictor based method was proposed [12]. And through this method, three main problems ((1) effect of "false water level, (2) controller parameter mismatches due to variant working condition, and (3) signal noise caused by uncertainties of drum water level") in drum water level control system were resolved. By employing generalized predictive control structures for inner and outer loops, a cascade model predictive control scheme for boiler drum water level control was designed [13]. In order to reject disturbances generated in boiler, a fuzzy supervisory scheme was proposed [14]. A robust multivariable controller using $H_{\infty}$ loop-shaping techniques was designed [15]. Due to the inaccessibility of some state variables of boiler system, a minimum-order observer was designed based on Luenberger's model to gain an estate state $x$ [16]. In this scheme a local controller was designed using Linear Quadratic Gaussian with Loop Transfer Recovery. The set points to the controller were modified whenever necessary 
by a supervisor partially based on fuzzy logic. An adaptive control application was applied to a $765 \mathrm{MW}$ large thermal power plant, and the control strategy decreased the operating costs and increased the quality of the generated electricity [17].

During the operation of the ship, disturbance from the sea is changeable and frequent, and the ship operation modes are also changeable. So it is difficult to have good performance of the ship boiler drum water level control. In order to overcome this problem, sliding mode control is considered in this system due to its advantages in dealing with uncertainties. But the control term in ship boiler drum water level is feed water rate, which is realized by the opening of the valve. So the control term needs to be smooth, and the chattering phenomenon in sliding mode control must be removed. In this paper, full-order sliding mode controller with smooth control is implemented to improve boiler drum water level system in the presence of model uncertainties. The proposed method can resolve the chattering problem and can be used in ship boiler drum water level successfully.

The rest of this paper is organized as follows. In Section 2, the problem in sliding mode control is stated. In Section 3, the full-order sliding mode controller with differentiable control is proposed. Through hiding the switching term in second derivation of control $u$, a differentiable control $u$ is obtained. Then the stability of this control law is proved with Lyapunov stability theory. In Section 4, the proposed method is used in boiler drum water level control, and the simulation is discussed. In Section 5, a conclusion is obtained.

\section{Problem Statement}

The high-order nonlinear system can be described as follows:

$$
\begin{gathered}
\dot{x}_{1}=x_{2}, \\
\dot{x}_{2}=x_{3}, \\
\vdots \\
\dot{x}_{n-1}=x_{n}, \\
\dot{x}_{n}=f(\mathbf{x}, t)+d(\mathbf{x}, t)+b(\mathbf{x}, t) u, \\
y=\mathbf{c}(\mathbf{x}, t) \mathbf{x},
\end{gathered}
$$

where $\mathbf{x}=\left[x_{1}, x_{2}, \ldots, x_{n-1}, x_{n}\right] \mathbf{x} \in R^{n}$ are the system states; $u$ is the control input; $y$ is the system output; $f(\mathbf{x}, t)$ and $b(\mathbf{x}, t)$ are both smooth functions; $d(\mathbf{x}, t)$ represents the external disturbances and parameter uncertainties.

In order to get a smooth control term $u$, chatteringfree full-order sliding mode control has been proposed in literature [11].

A terminal sliding mode (TSM) manifold for system (1) was selected as follows:

$$
s=\dot{x}_{n}+c_{n} \operatorname{sgn}\left(x_{n}\right)\left|x_{n}\right|^{\alpha_{n}}+\cdots+c_{1} \operatorname{sgn}\left(x_{1}\right)\left|x_{1}\right|^{\alpha_{1}},
$$

where $c_{i}$ and $\alpha_{i}(i=1,2, \ldots, n)$ are constants. $c_{i}$ are selected such that the polynomial $p^{n}+c_{n} p^{n-1}+\cdots+c_{2} p+c_{1}$ is Hurwitz. $\alpha_{i}$ can be selected as follows:

$$
\begin{aligned}
\alpha_{1} & =\alpha, \quad n=1, \\
\alpha_{i-1} & =\frac{\alpha_{i} \alpha_{i+1}}{2 \alpha_{i+1}-\alpha_{i}}, \quad i=2, \ldots, n \forall n \geq 2,
\end{aligned}
$$

where $\alpha_{n+1}=1, \alpha_{n}=\alpha, \alpha \in(1-\varepsilon, 1)$, and $\varepsilon \in(0,1)$.

The control term can be designed as follows:

$$
\begin{aligned}
u= & b^{-1}(\mathbf{x}, t)\left(u_{e q}+u_{n}\right), \\
u_{e q}= & -f(x, t)-c_{n} \operatorname{sgn}\left(x_{n}\right)\left|x_{n}\right|^{\alpha_{n}}-\cdots \\
& -c_{1} \operatorname{sgn}\left(x_{1}\right)\left|x_{1}\right|^{\alpha_{1}}, \\
\dot{u}_{n}+T u_{n}= & v, \\
v= & -\left(k_{d}+k_{T}+\eta\right) \operatorname{sgn}(s),
\end{aligned}
$$

where $T, k_{d}, k_{T}$, and $\eta$ satisfy the following conditions: $T \geq$ $0,|\dot{d}(\mathbf{x}, t)| \leq k_{d},|d(\mathbf{x}, t)| \leq k_{T} / T$, and $\eta>0 . \operatorname{sgn}(s)$ represents the sign function of $s$.

$$
\operatorname{sgn}(s)= \begin{cases}1, & s>1, \\ 0, & s=0, \\ -1, & s<0 .\end{cases}
$$

From the method introduced above, a continuous control term can be obtained, but the control term is not smooth. Due to the fact that the opening of valve and its change in velocity cannot change suddenly, the objective is to get a smooth control.

\section{Full-Order Sliding Mode Controller with Differentiable Control}

The system described in (1) is considered. And suppose that the functions $f(\mathbf{x}, t), b(\mathbf{x}, t)$, and $d(\mathbf{x}, t)$ are differentiable. $\dot{f}(\mathbf{x}, t)$ and $\dot{b}(\mathbf{x}, t)$ are known. So system (1) can be extended as follows:

$$
\begin{gathered}
\dot{x}_{1}=x_{2}, \\
\dot{x}_{2}=x_{3}, \\
\vdots \\
\dot{x}_{n-1}=x_{n}, \\
\dot{x}_{n}=x_{n+1}, \\
\dot{x}_{n+1}=\dot{f}(\mathbf{x}, t)+\dot{d}(\mathbf{x}, t)+\dot{b}(\mathbf{x}, t) u+b(\mathbf{x}, t) \dot{u}, \\
y=\mathbf{c}(\mathbf{x}, t) \mathbf{x} .
\end{gathered}
$$


The TSM manifold can be selected as follows:

$$
\begin{aligned}
s= & x_{1}^{n+1}+c_{n+1} \operatorname{sgn}\left(x_{1}^{(n)}\right)\left|x_{1}^{(n)}\right|^{\alpha_{n}} \\
& +c_{n} \operatorname{sgn}\left(x_{1}^{(n-1)}\right)\left|x_{1}^{(n-1)}\right|^{\alpha_{n-1}}+\cdots \\
& +c_{1} \operatorname{sgn}\left(x_{1}\right)\left|x_{1}\right|^{\alpha_{1}} \\
= & \dot{x}_{n+1}+c_{n+1} \operatorname{sgn}\left(x_{n+1}\right)\left|x_{n+1}\right|^{\alpha_{n+1}}+c_{n} \operatorname{sgn}\left(x_{n}\right)\left|x_{n}\right|^{\alpha_{n}} \\
& +\cdots+c_{1} \operatorname{sgn}\left(x_{1}\right)\left|x_{1}\right|^{\alpha_{1}},
\end{aligned}
$$

where $c_{i}$ and $\alpha_{i}$ satisfy the conditions requirements mentioned in Section 2. When the motion of the system is constrained to the manifold $s=0$, the motion is governed by $\dot{x}_{n+1}=-c_{n+1} \operatorname{sgn}\left(x_{n+1}\right)\left|x_{n+1}\right|^{\alpha_{n+1}}-\cdots-c_{1} \operatorname{sgn}\left(x_{1}\right)\left|x_{1}\right|^{\alpha_{1}}$. The choices of $\mathbf{c}(\mathbf{x}, t)$ need to guarantee that $\mathbf{x}(t)$ tends to zero as $t$ tends to infinity. The choice of $\mathbf{c}(\mathbf{x}, t)$ can change the rate of the convergence. So $c_{i}(i=1,2, \ldots, n+1)$ in $\mathbf{c}(x, t)$ need to be selected to ensure that the polynomial $p^{n}+c_{n} p^{n-1}+\cdots+c_{2} p+c_{1}$ is Hurwitz. $a_{i}(i=1,2, \ldots, n+1)$ are selected according to (3).

Assumption 1. The disturbance term in system (1) satisfies the condition as follows:

$$
\begin{aligned}
& \ddot{d}(\mathbf{x}, t) \leq h_{d}, \\
& d(\mathbf{x}, t) \leq k_{d},
\end{aligned}
$$

where $h_{d}$ and $k_{d}$ are constants.

This assumption is realistic during the operation of the ship. During the sailing of the ship, disturbance suffered is main wave disturbance. And the wave disturbance in sea is usually smooth.

In order to simplify the process, the function $b(\mathbf{x}, t)$ is supposed to be an invariable matrix, and $b(\mathbf{x}, t)$ is expressed as $b$.

So system (6) can be rewritten as follows:

$$
\begin{gathered}
\dot{x}_{1}=x_{2}, \\
\dot{x}_{2}=x_{3}, \\
\vdots \\
\dot{x}_{n-1}=x_{n}, \\
\dot{x}_{n}=x_{n+1}, \\
\dot{x}_{n+1}=\dot{f}(\mathbf{x}, t)+\dot{d}(\mathbf{x}, t)+b \dot{u}, \\
y=\mathbf{c}(\mathbf{x}, t) \mathbf{x} .
\end{gathered}
$$

The control $u$ can be designed as follows:

$$
\dot{u}=b^{-1}\left(\dot{u}_{e q}+\dot{u}_{x}\right)
$$

$$
\begin{aligned}
\dot{u}_{e q}= & -\dot{f}(x, t)-c_{n+1} \operatorname{sgn}\left(x_{n+1}\right)\left|x_{n+1}\right|^{\alpha_{n+1}} \\
& -c_{n} \operatorname{sgn}\left(x_{n}\right)\left|x_{n}\right|^{\alpha_{n}}-\cdots \\
& -c_{1} \operatorname{sgn}\left(x_{1}\right)\left|x_{1}\right|^{\alpha_{1}}, \\
\ddot{u}_{x}+T \dot{u}_{x}= & v, \\
v= & -\left(h_{d}+h_{T}+\eta\right) \operatorname{sgn}(s),
\end{aligned}
$$

where $\eta, T$ are all positive constants; $h_{T}$ is selected to satisfy the following condition:

$$
h_{T}>T k_{d}
$$

Proof. The Lyapunov function is selected as

$$
V(s)=\frac{1}{2} s^{2} .
$$

According to (10) and (11), the manifold in (7) can be rewritten as

$$
\begin{aligned}
& s=\dot{d}(\mathbf{x}, t)+\dot{u}_{x}, \\
& \dot{s}=\ddot{d}(\mathbf{x}, t)+\ddot{u}_{x} .
\end{aligned}
$$

Hence

$$
\dot{V}(s)=s \dot{s}=s\left(\ddot{d}(\mathbf{x}, t)+\ddot{u}_{x}\right) .
$$

Substituting (12) into (18),

$$
\begin{aligned}
\dot{V}(s) & =s\left(\ddot{d}(\mathbf{x}, t)+v-T \dot{u}_{x}\right) \\
& =s\left(\ddot{d}(\mathbf{x}, t)-\left(h_{d}+h_{T}+\eta\right) \operatorname{sgn}(s)-T \dot{u}_{x}\right) \\
& =\left(\ddot{d}(\mathbf{x}, t) s-h_{d}|s|\right)+\left(-T \dot{u}_{x} s-h_{T}|s|\right)-\eta|s| .
\end{aligned}
$$

According to (12), $\dot{u}_{x}$ and $u_{x}$ can be gotten.

$$
\begin{aligned}
& \dot{u}_{x}(t)=\left(\frac{v}{T}\right)+c_{1} e^{-T\left(t-t_{0}\right)}, \\
& u_{x}(t)=\left(\frac{v}{T}\right) t+\left(-\frac{c_{1}}{T}\right) e^{-T\left(t-t_{0}\right)}+c_{2} .
\end{aligned}
$$

The initial values of $\dot{u}_{x}$ and $u_{x}$ are assumed to be zeros, so the values $c_{1}$ and $c_{2}$ can be gotten as

$$
\begin{aligned}
& c_{1}=\dot{u}_{x}\left(t_{0}\right)-\left(\frac{v}{T}\right), \\
& c_{2}=u_{x}\left(t_{0}\right)+\left(\frac{1}{T}\right) \dot{u}_{x}\left(t_{0}\right)-\left(\frac{v}{T}\right) t_{0}-\left(\frac{v}{T^{2}}\right) .
\end{aligned}
$$

The initial time is supposed to be zero, so

$$
\begin{aligned}
c_{1} & =-\frac{v}{T}, \\
c_{2} & =-\frac{v}{T^{2}} \\
\dot{u}_{x}(t) & =\left(\frac{v}{T}\right)\left(1-{ }_{1} e^{-T\left(t-t_{0}\right)}\right), \\
u_{x}(t) & =\left(\frac{v}{T}\right) t+\left(\frac{v}{T^{2}}\right) e^{-T\left(t-t_{0}\right)}-\left(\frac{v}{T^{2}}\right) .
\end{aligned}
$$


According to (16) and (24), the following relationship can be obtained under the condition $u_{x}(0)=0$ :

$$
h_{T} \geq T k_{d} \geq T\left|u_{x}(t)\right|_{\max } \geq T\left|u_{x}(t)\right|
$$

Hence

$$
\begin{aligned}
\dot{V}(s) & =\left(\ddot{d}(\mathbf{x}, t) s-h_{d}|s|\right)+\left(-T \dot{u}_{x} s-h_{T}|s|\right)-\eta|s| \\
& \leq-\eta|s| .
\end{aligned}
$$

So it is proved that system (6) can reach $s=0$ in finite time. Once the condition $s=0$ is reached, the system will behave as the following form:

$$
\begin{aligned}
\dot{x}_{n+1}= & -c_{n+1} \operatorname{sgn}\left(x_{n+1}\right)\left|x_{n+1}\right|^{\alpha_{n+1}}-c_{n} \operatorname{sgn}\left(x_{n}\right)\left|x_{n}\right|^{\alpha_{n}} \\
& -\cdots-c_{1} \operatorname{sgn}\left(x_{1}\right)\left|x_{1}\right|^{\alpha_{1}}, \\
y= & \mathbf{c}(\mathbf{x}, t) \mathbf{x} .
\end{aligned}
$$

0 .

The system will converge to zeros in finite time along $s=$

In order to get $s$, a function $g(t)$ can be defined as

$$
\begin{aligned}
& g(t)=\int_{0}^{t} s(t) d t=x_{n+1} \\
& +\int_{0}^{t}\left(c_{n+1} \operatorname{sgn}\left(x_{n+1}\right)\left|x_{n+1}\right|^{\alpha_{n+1}}+\cdots\right. \\
& \left.\quad+c_{1} \operatorname{sgn}\left(x_{1}\right)\left|x_{1}\right|^{\alpha_{1}}\right) d t .
\end{aligned}
$$

$\operatorname{sgn}(s)$ can be gotten by the following equation:

$$
\operatorname{sgn}(s)=\operatorname{sgn}(g(t)-g(t-\tau)),
$$

where $\tau$ is the sampling time.

The variables in (29) can be gotten with sensors except $x_{n+1}$. In order to get $s, x_{n+1}$ can be obtained by $x_{n+1}=\dot{x}_{n}$ approximately; that is,

$$
x_{n+1}=\frac{x_{n}(t)-x_{n}(t-\tau)}{\tau} .
$$

\section{The Application in Ship Boiler Drum Water Level Control}

In this section, the design of full-order sliding mode controller for the system is described. First, the schematic of the boiler system in ship is described. Assuming the steam mass rate to be constant, the system can be simplified as a single input single output system, and the change in steam rate can be regarded as disturbance. This section is organized as two parts, one of which is the boiler system description; the other is full-order sliding mode controller design.

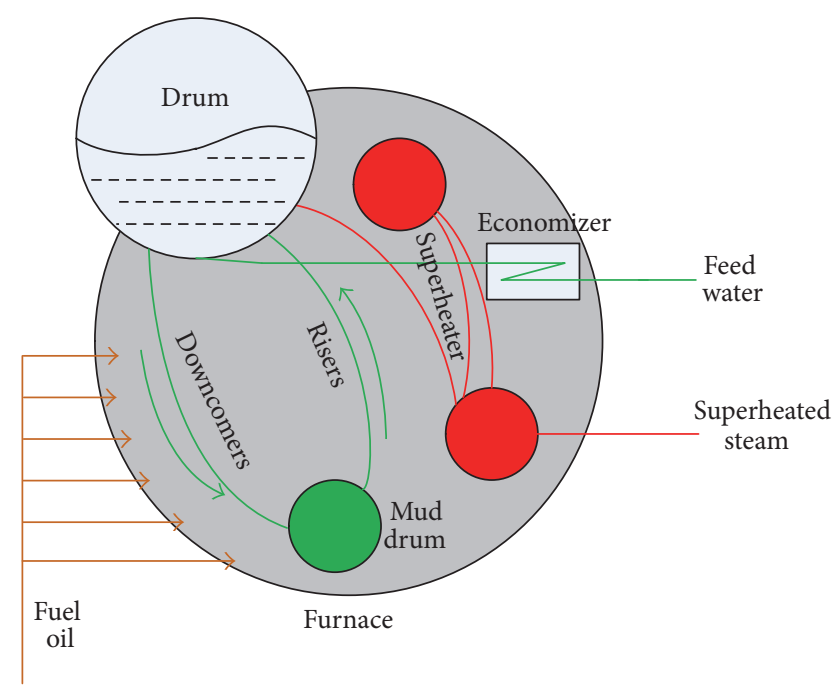

FIgURE 1: Schematic of the boiler unit.

4.1. Boiler System Description. Due to the frequency disturbance during the voyage of the ship, it is important to have an effective control strategy for the drum water level control system. The boiler drum water level system is shown in Figure 1.

The operation process of the boiler is stated as follows. First, the feed water is supplied into the boiler after being heated in the economizer. Next, due to the higher density of the feed water, it will flow into the mud drum. Then, the feed water would be heated in risers under the burning of the fuel, and the feed water turns into saturated mixture of water and steam. Finally, the steam is separated from the mixture and flows out of the drum through superheater.

Modeling of boiler unit has received substantial development as a fundamental. Bell et al. $[18,19]$ and de Mello $[20,21]$ are the two main researchers in this area. In this paper, a time varying model obtained from Astrom is used. In this model, the water level is regarded as output in $G(s)$ and $G_{S H}(s)$, while the opening of the feed water valve and the steam mass rate are regarded as input separately in $G(s)$ and $G_{S H}(s)$. The change of the steam mass rate is regarded as system disturbance.

$$
\begin{aligned}
G(s) & =\frac{H(s)}{U_{1}(s)}=\frac{\lambda}{(s+\lambda)} \frac{\alpha_{1}}{s\left(1+\tau_{1} s\right)}, \\
G_{S H}(s) & =\frac{\beta}{1+\tau_{2} s}-\frac{\alpha_{2}}{s},
\end{aligned}
$$

where $\lambda$ denotes inertia coefficient, $\tau_{1}$ and $\tau_{2}$ are the time constants, and $\alpha_{1}, \alpha_{2}$, and $\beta$ are constant gains. The states equations of system (32) are shown as follows:

$$
\begin{aligned}
& \dot{x}_{1}=x_{2}, \\
& \dot{x}_{2}=x_{3}, \\
& \dot{x}_{3}=A x_{2}+B x_{3}+u+d(\mathbf{x}),
\end{aligned}
$$




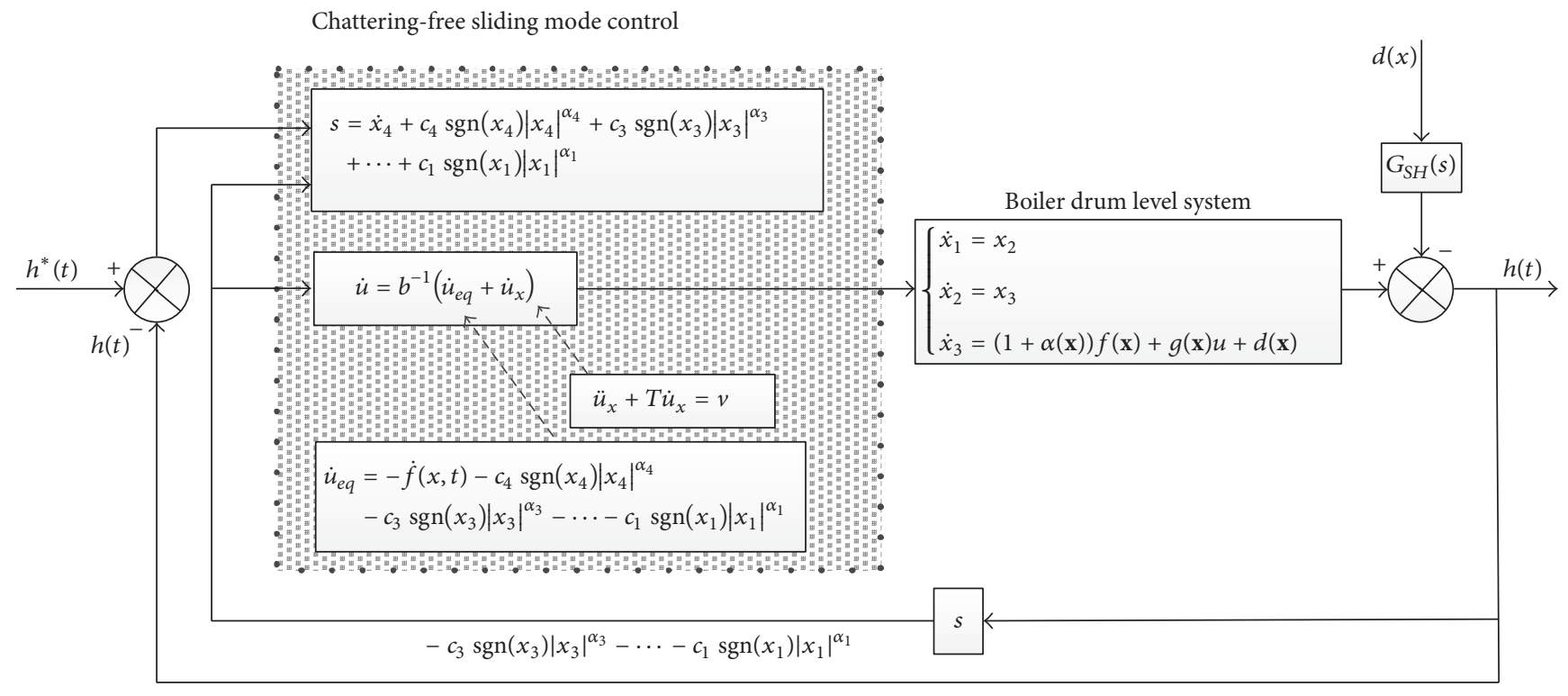

FIGURE 2: Schematic of full-order sliding mode control in boiler drum water level system.

where $A$ and $B$ are constants. $d(\mathbf{x})$ denotes the system disturbance, and $d(\mathbf{x})$ are restricted with the following relationships:

$$
\begin{aligned}
& \ddot{d}(\mathbf{x}) \leq h_{d}, \\
& d(\mathbf{x}) \leq k_{d} .
\end{aligned}
$$

4.2. Sliding Mode Controller Design for Boiler Drum Water Level System. In this section, full-order sliding mode controller is designed for boiler drum water level system and the schematic of the control strategy is shown in Figure 2. $h^{*}(t)$ and $h(t)$ denote the desired signal and actual signal of drum water level, respectively, and $d(x)$ denotes the steam mass of the boiler. The structure of the chattering-free sliding mode control is displayed in the box filled with black spots. $G_{S H}(s)$ and state equations of $\mathbf{x}$ are the models of the boiler drum water system.

The model of this system is based on the model of function (34), and the boiler drum water level system can be extended as follows:

$$
\begin{aligned}
& \dot{x}_{1}=x_{2}, \\
& \dot{x}_{2}=x_{3}, \\
& \dot{x}_{3}=x_{4}, \\
& \dot{x}_{4}=A x_{3}+B x_{4}+\dot{u}+\dot{d}(\mathbf{x}) .
\end{aligned}
$$

According to (7), the manifold can be designed as follows:

$$
\begin{aligned}
s= & \dot{x}_{4}+c_{4} \operatorname{sgn}\left(x_{4}\right)\left|x_{4}\right|^{\alpha_{4}}+c_{3} \operatorname{sgn}\left(x_{3}\right)\left|x_{3}\right|^{\alpha_{3}}+\cdots \\
& +c_{1} \operatorname{sgn}\left(x_{1}\right)\left|x_{1}\right|^{\alpha_{1}} .
\end{aligned}
$$

TABLE 1: Partial parameters in the simulations.

\begin{tabular}{cccccc}
\hline$\lambda$ & 0.1 & $\beta$ & 3.6 & $A$ & $-10 / 30$ \\
$\alpha_{1}$ & 0.037 & $\alpha_{2}$ & 0.053 & $B$ & $-301 / 30$ \\
$\tau_{1}$ & 30 & $\tau_{2}$ & 15 & $T$ & 0.1 \\
\hline
\end{tabular}

And the control term $u$ can be designed as follows:

$$
\dot{u}=b^{-1}\left(\dot{u}_{e q}+\dot{u}_{x}\right),
$$

where $\dot{u}_{e q}$ and $\dot{u}_{x}$ can be obtained according to (11) and (12).

\section{Simulation of the Control Design, Results, and Discussion}

Simulation experiments are done to investigate the effect of proposed control strategy. The parameters in system (32), (33), and (34) and partial parameter in the controller are listed in Table 1.

According to (3), $\alpha_{i}(i=1,2, \ldots, 4)$ in (37) can be selected as $\boldsymbol{\alpha}=[0.2,0.25,0.33,0.5]$, and, according to Hurwitz condition, $c_{i},(i=1,2, \ldots, 4)$ in (37) can be selected as $\mathbf{c}=$ $[100,60,97,18]$.

The disturbance term $d(\mathbf{x})$ in the model is shown in Figure 3 . The disturbance is selected as band limited white noise, whose noise power is 0.1 , and the sample time is $10 \mathrm{~s}$.

In this paper, a step change in water level is given to the system. The system is operating at the point with water level of $H=0.8 \mathrm{~m}$ and the control $u$ is $u=7 \mathrm{~mA}$. The simulation results are shown in Figures 4-7. Figure 4 shows time response of the closed-loop boiler drum water level system of $\Delta H=0.2 \mathrm{~m}$ with full-order sliding mode controller. From the simulation, the overshoot $\sigma$ is $4 \%$, and 


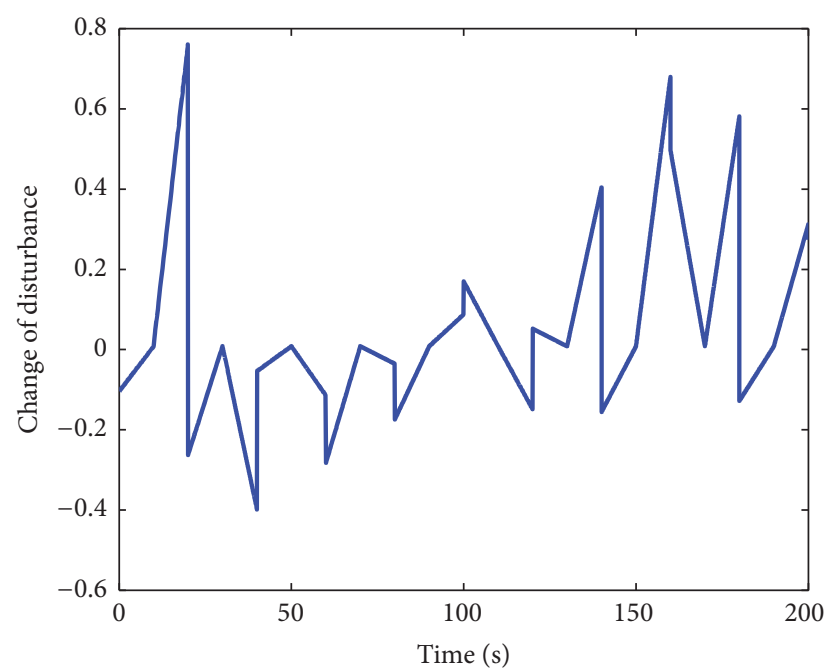

- Disturbance in model

FIgURE 3: Realistic variation of disturbance.

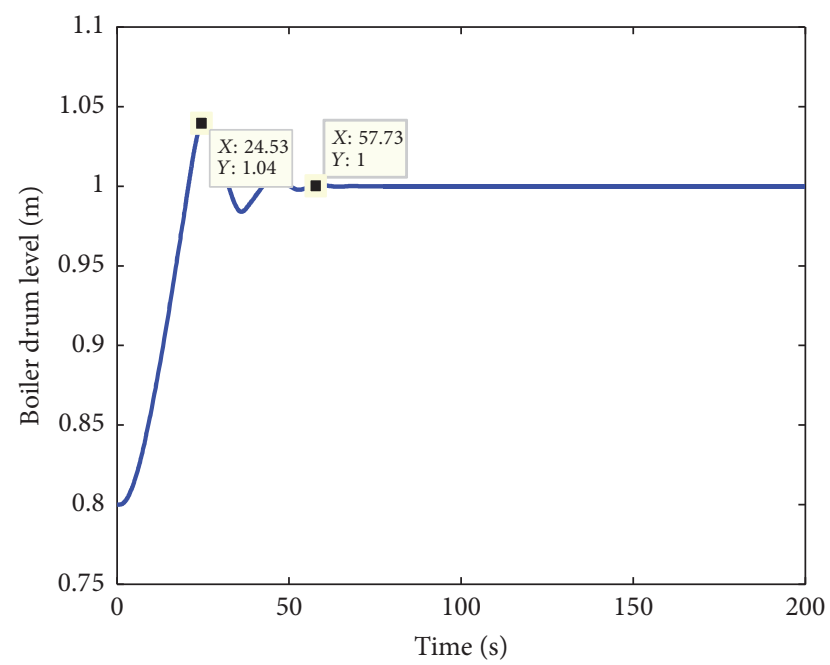

Figure 4: Variation of the drum water level.

the setting time is $57.73 \mathrm{~s}$ without steady state error. It can be observed that drum water level demonstrates a stable behavior, and its performance is almost not affected by the disturbance shown in Figure 3.

The state variables of the system and its partially enlarged view are displayed in Figure 5. The actual control signal and its derivative are displayed in Figures 6 and 7 separately. It can be seen that although there is a switching function in signal $v$, the actual control signal $u$ is smooth and its derivative is continuous.

From the simulation results, the proposed full-order sliding mode control can lead to a satisfied performance for the boiler drum water level system. The proposed control strategy can also be implemented on other practical process control systems like the boiler drum water level system.

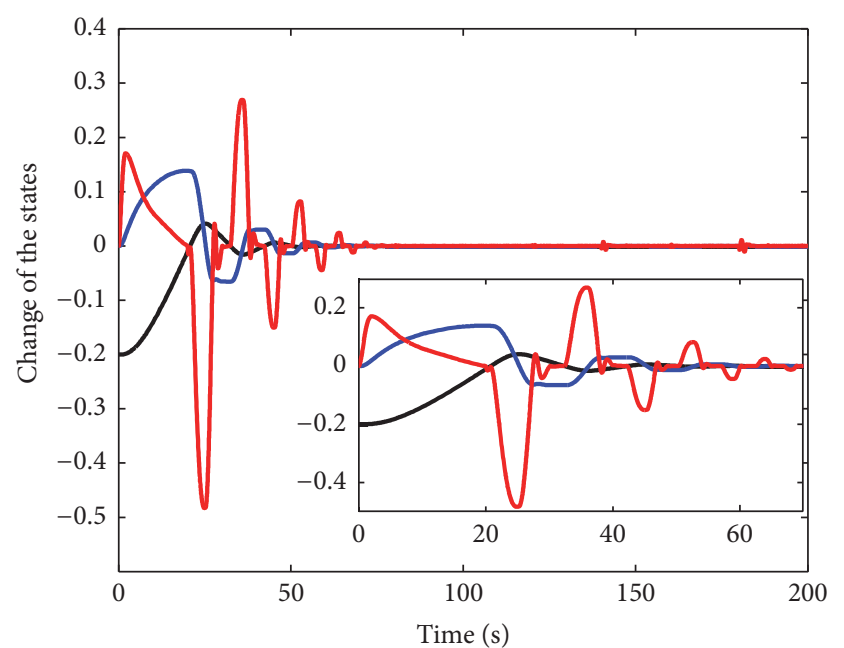

_ Errors of drum level (m)

- Change in velocity of drum level $(\mathrm{m} / \mathrm{s})$

- Acceleration of drum level $\left(\mathrm{m} / \mathrm{s}^{2}\right)$

FIGURE 5: State variables of the system.

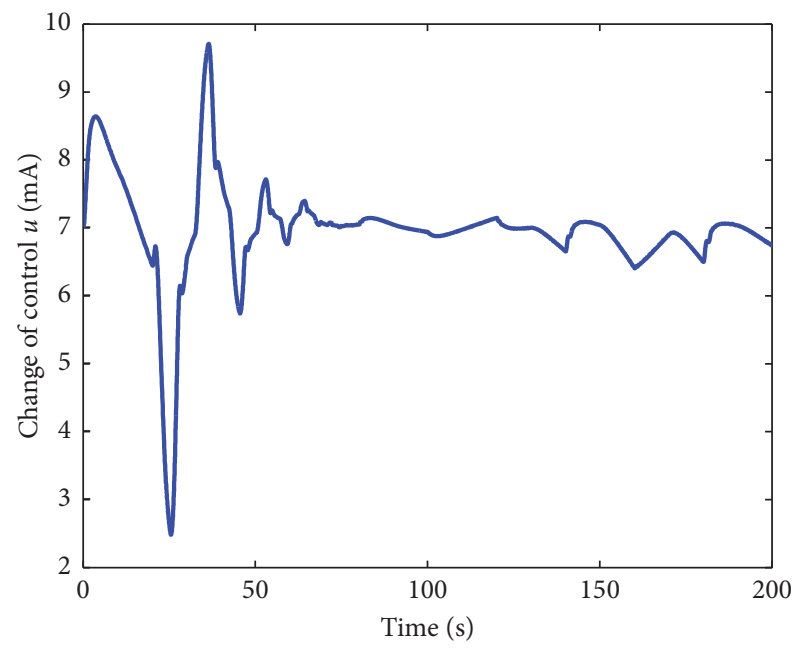

— Chattering-free SMC

Figure 6: Control of the drum water level control system.

\section{Conclusions}

Sliding mode control is an effective strategy to deal with problems such as nonlinearity, parameter mismatch, disturbance, and nonprecision of the system model. But the application of the algorithm is greatly restricted by chattering phenomenon existing in the control signal. In this paper, a smooth fullorder sliding mode control is proposed. And the chattering phenomenon has been resolved. This new method can satisfy the demand of some applications that need a smooth control signal which is especially important in process control. Stable control of the drum water level is of great importance for the operation of ship boiler. The drum water level must be kept as a constant. The proposed control strategy in this paper is 


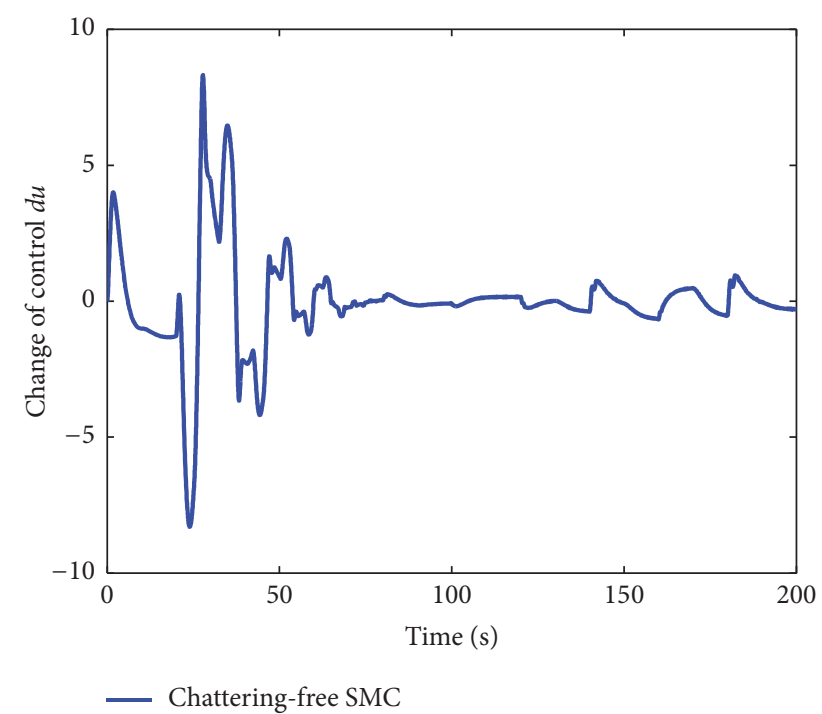

FIGURE 7: Change in velocity of the control signal.

applied to drum water level system in the absence of model uncertainties. According to the results, the water level has an ideal performance in tracking of water level commands. And the control signal is smooth which is required in practical process control application.

\section{Competing Interests}

The authors declare that there are no competing interests regarding the publication of this paper.

\section{Acknowledgments}

This work was supported by the National Natural Science Foundation (NNSF) of China under Grant 51279036 and Grant 51579047 and Fundamental Research Funds for the Central Universities (HEUCF160408).

\section{References}

[1] Z. Meng, W. Ren, and Z. You, "Distributed finite-time attitude containment control for multiple rigid bodies," Automatica, vol. 46, no. 12, pp. 2092-2099, 2010.

[2] L. Fridman, "Sliding mode enforcement after 1990: main results and some open problems," in Sliding Modes after the First Decade of the 21st Century, L. Fridman, J. Moreno, and R. Iriarte, Eds., vol. 412 of Lecture Notes in Control and Information Sciences, pp. 3-27, Springer, Berlin, Germany, 1990.

[3] V. I. Utkin, Sliding Modes in Control and Optimization, Springer, Berlin, Germany, 1992.

[4] G. Bartolini, A. Ferrara, and E. Usai, "Chattering avoidance by second-order sliding mode control," IEEE Transactions on Automatic Control, vol. 43, no. 2, pp. 241-246, 1998.

[5] A. Levant, "Robust exact differentiation via sliding mode technique," Automatica, vol. 34, no. 3, pp. 379-384, 1998.
[6] A. Levant, "Universal single-input-single-output (SISO) sliding-mode controllers with finite-time convergence," IEEE Transactions on Automatic Control, vol. 46, no. 9, pp. 1447-1451, 2001.

[7] A. Levant, "Homogeneity approach to high-order sliding mode design," Automatica, vol. 41, no. 5, pp. 823-830, 2005.

[8] A. Levant, "Principles of 2-sliding mode design," Automatica, vol. 43, no. 4, pp. 576-586, 2007.

[9] Y. B. Shtessel, I. A. Shkolnikov, and M. D. J. Brown, "Asymptotic second-order smooth sliding mode control," Asian Journal of Control, vol. 5, no. 4, pp. 498-504, 2003.

[10] H. Du, X. Yu, M. Z. Chen, and S. Li, "Chattering-free discretetime sliding mode control," Automatica, vol. 68, pp. 87-91, 2016.

[11] Y. Feng, F. Han, and X. Yu, "Chattering free full-order slidingmode control," Automatica, vol. 50, no. 4, pp. 1310-1314, 2014.

[12] N. Yu, W. Ma, and M. Su, "Application of adaptive Grey predictor based algorithm to boiler drum level control," Energy Conversion and Management, vol. 47, no. 18-19, pp. 2999-3007, 2006.

[13] M. Xu, S. Li, and W. Cai, "Cascade generalized predictive control strategy for boiler drum level," ISA Transactions, vol. 44, no. 3, pp. 399-411, 2005.

[14] A. Abdennour, "Intelligent supervisory system for drum type boilers during severe disturbances," International Journal of Electrical Power and Energy System, vol. 22, no. 5, pp. 381-387, 2000.

[15] W. Tan, H. J. Marquez, and T. Chen, "Multivariable robust controller design for a boiler system," IEEE Transactions on Control Systems Technology, vol. 10, no. 5, pp. 735-742, 2002.

[16] H. Moradi and F. Bakhtiari-Nejad, "Improving boiler unit performance using an optimum robust minimum-order observer," Energy Conversion and Management, vol. 52, no. 3, pp. 17281740, 2011.

[17] I. Kocaarslan and E. Çam, "An adaptive control application in a large thermal combined power plant," Energy Conversion and Management, vol. 48, no. 1, pp. 174-183, 2007.

[18] R. D. Bell and K. J. Astrom, "Simplified models of boilerturbine units," Tech. Rep. TFRT-3191, Department of Automatic Control, Lund Institute of Technology, 1987.

[19] K. J. Åströma and R. D. Bell, "Drum-boiler dynamics," Automatica, vol. 36, no. 3, pp. 363-378, 2000.

[20] F. P. de Mello, "Boiler models for system dynamic performance studies," IEEE Transactions on Power Systems, vol. 6, no. 1, pp. 66-74, 1991.

[21] F. P. de Mello, "Dynamic models for fossil fueled steam units in power system studies," IEEE Transactions on Power Systems, vol. 6, no. 2, pp. 753-761, 1991. 


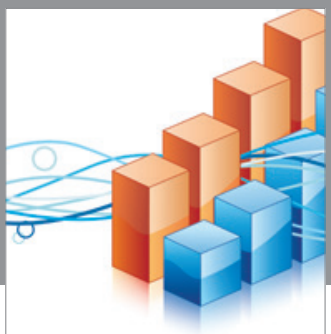

Advances in

Operations Research

vatem alat4

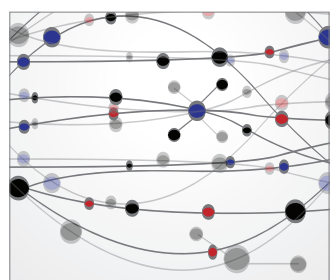

\section{The Scientific} World Journal
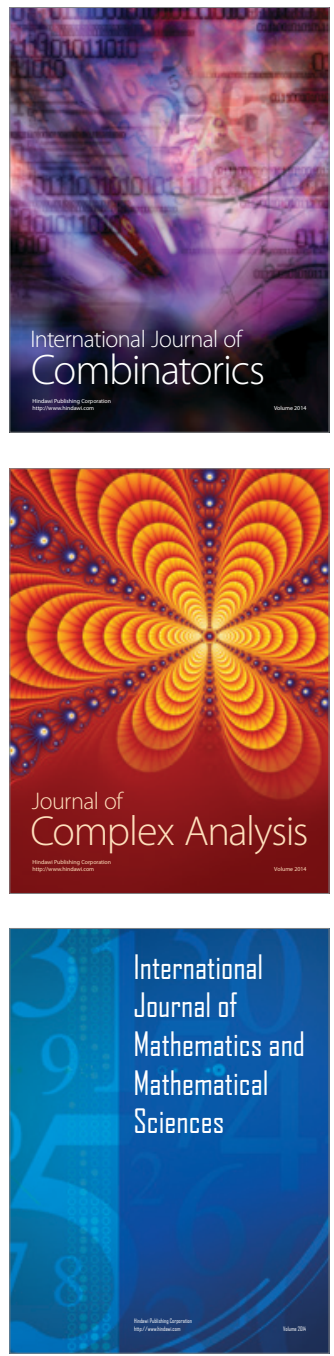
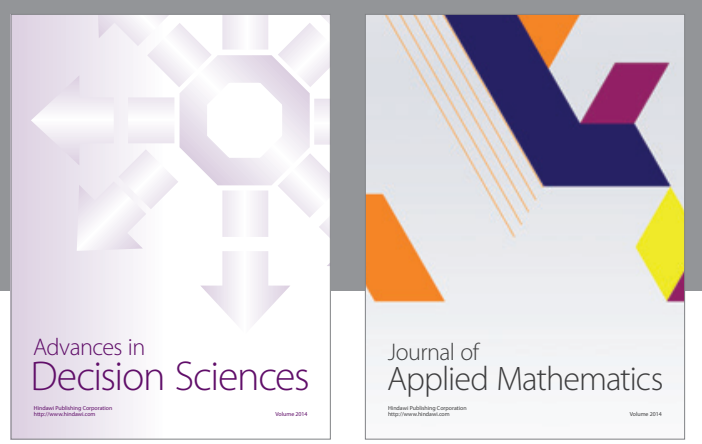

Algebra

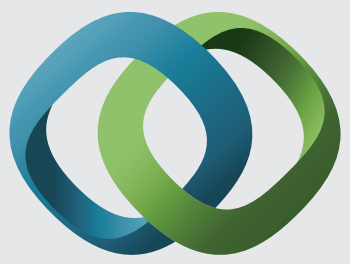

\section{Hindawi}

Submit your manuscripts at

http://www.hindawi.com
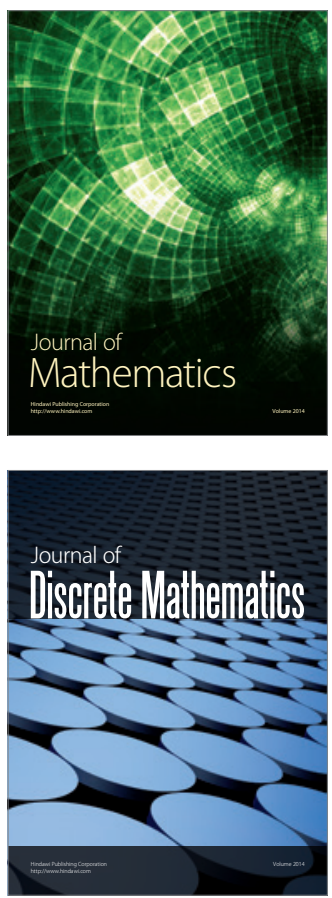

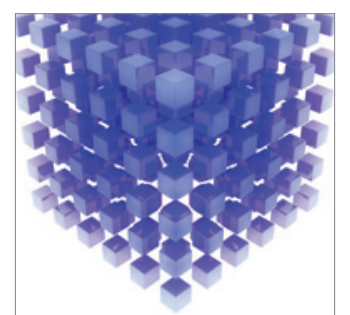

Mathematical Problems in Engineering
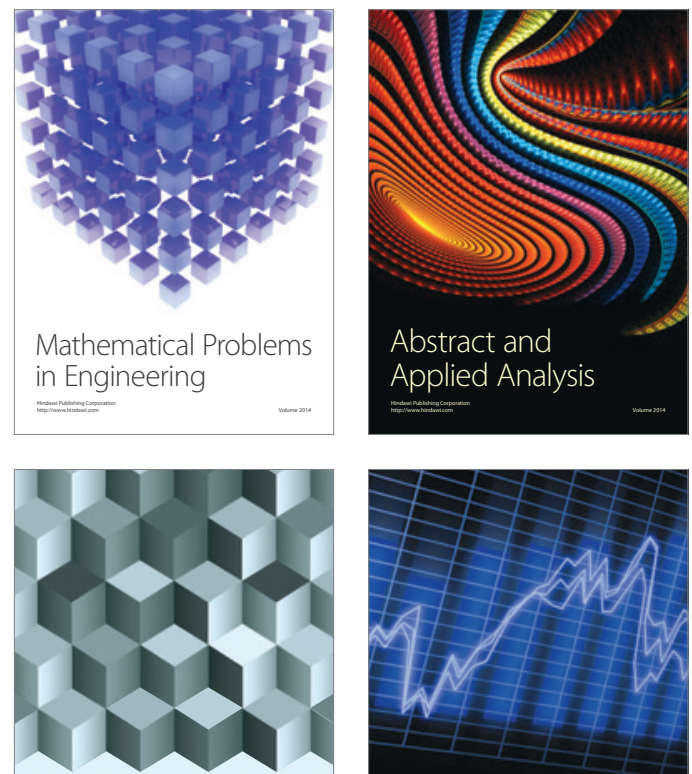

Journal of

Function Spaces

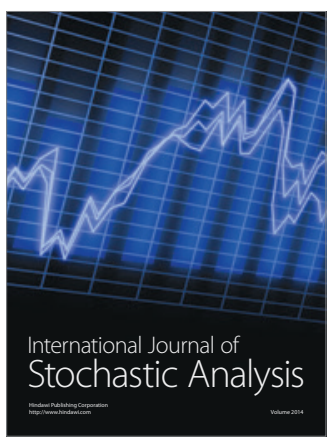

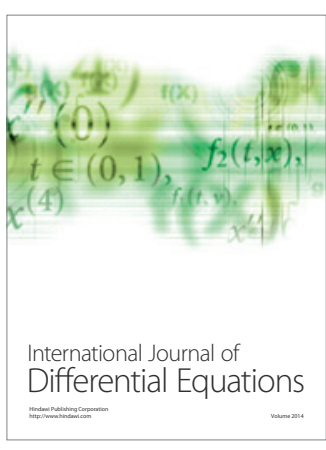
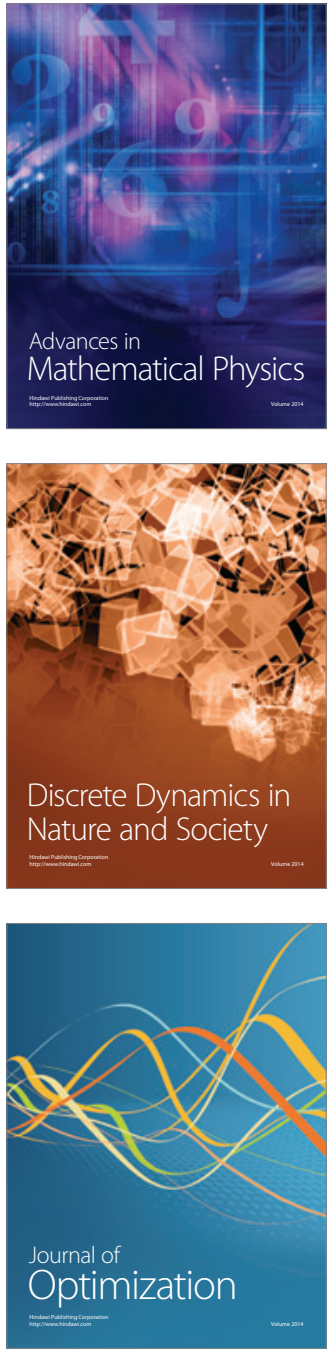